\title{
Prolonged-Release Suspension for Injection Dosage Form
}

National Cancer Institute

\section{Source}

National Cancer Institute. Prolonged-Release Suspension for Injection Dosage Form. NCI

Thesaurus. Code C149877.

Liquid sterile preparation consisting of a suspension intended for administration by injection; the active substance(s) are released over an extended period of time. 